\title{
COMUNIDADE MICROBIANA E MESOFAUNA EDÁFICAS EM SOLO SOB CAATINGA NO SEMI-ÁRIDO DA PARAÍBA ${ }^{(1)}$
}

\author{
Patrícia Carneiro Souto(2), Jacob Silva Souto ${ }^{(3)}$, José Romilson Paes \\ de Miranda ${ }^{(2)}$, Rivaldo Vital dos Santos ${ }^{(3)}$ \& Allyson Rocha Alves ${ }^{(4)}$
}

\begin{abstract}
RESUMO
A atividade biológica do solo é responsável por inúmeras transformações físicas e químicas dos resíduos orgânicos que são depositados, mantendo, assim, a sustentabilidade do ambiente. O presente estudo objetivou avaliar a distribuição da comunidade microbiana e da mesofauna edáfica no semi-árido da Paraíba. Para determinação da população de microrganismos, foram coletadas amostras de solo na profundidade de 0-15 $\mathrm{cm}$. A contagem total de fungos e de bactérias foi realizada em meios de cultura específicos. A extração da mesofauna foi feita pelo método de Berlese-Tullgren modificado. Oscilações no conteúdo de água do solo e na temperatura promoveram variações na população microbiana. A população de fungos foi superior à de bactérias nos dois anos de observação, provavelmente devido ao pH do solo da área de estudo, que é ligeiramente ácido. O índice de diversidade de Shannon (H) e o de Pielou (e) variaram de acordo com a época de coleta. Os grupos mais freqüentes da mesofauna do solo foram Diptera $(42,5 \%)$, Acarinae $(40,3 \%)$ e Collembola $(8,8 \%)$, indicando que esses organismos possuem papel importante na ciclagem de nutrientes em área de Caatinga.
\end{abstract}

Termos de indexação: biodiversidade do solo, fauna do solo, vegetação xerófila.

\section{SUMMARY: SOIL MICROBIAL COMMUNITY AND MESOFAUNA UNDER DRY FOREST VEGETATION IN THE SEMI-ARID REGION OF PARAÍBA, BRAZIL}

The biological soil activity is responsible for several physical and chemical transformations of deposited organic residues, therefore maintaining the environmental

\footnotetext{
(1) Parte da Tese de Doutorado do primeiro autor apresentada ao Programa de Pós-Graduação em Agronomia, área de concentração em Solos e Nutrição Mineral de Plantas, da Universidade Federal da Paraíba - UFPB. Recebido para publicação em julho de 2006 e aprovado em outubro de 2007.

${ }^{(2)}$ Professor da Unidade Acadêmica de Agronomia e Tecnologia de Alimentos, Universidade Federal de Campina Grande UFCG. CEP 58840-000 Pombal (PB). E-mail: pcarneirosouto@yahoo.com.br

${ }^{(3)}$ Professor Associado, Unidade Acadêmica de Engenharia Florestal, Universidade Federal de Campina Grande - UFCG. Caixa Postal 64, CEP 58700-970 Patos (PB). E-mail: jacob_souto@yahoo.com.br

(4) Doutorando em Ciências Florestais, Universidade Federal Rural de Pernambuco - UFRPE. Rua Dom Manoel de Medeiros s/n, Dois Irmãos, CEP 52171-900 Recife (PE). E-mail: allyson_engenharia@yahoo.com.br
} 


\begin{abstract}
sustainability. The aim of this study was to evaluate the distribution of the soil microbial community and mesofauna in a dry forest (Caatinga) in the semi-arid region of Paraíba, northeastern Brazil. To determine the microorganism population soil samples from the 0 $15 \mathrm{~cm}$ soil layer were evaluated. Total counts of fungi and bacteria were evaluated in specific culture media. The Berleusse-Tüllgren modified method was used to extract the soil mesofauna. Oscillations in the soil water content and high temperatures promoted variations in the microbial population. The fungi population was larger than that of bacteria in both years of the study period, probably due to the slightly acidic soil pH. Shannon's index $(H)$ and Pielou's index (e) also varied according to the season of the year. The most important mesofauna groups are Díptera (42.5\%), Acarinae (40.3\%) and Collembola (8.8\%). These groups play an important role in nutrient cycling in dry forest sites.
\end{abstract}

Index terms: Soil biodiversity, soil fauna, xerophilous vegetation.

\section{INTRODUÇÃO}

Os principais fatores que controlam os processos de transformação da matéria orgânica no solo (MOS) são a quantidade e qualidade do material, o ambiente físico e químico e os organismos decompositores. Entre os organismos, bactérias e fungos apresentam altos valores de biomassa e metabolismo respiratório e têm grande participação no processo de decomposição da MOS (Toledo, 2003; Lejon et al., 2005).

Uma flora variada de bactérias e fungos pode realizar a degradação completa de material orgânico de restos de plantas e animais, mas, em prática, eles raramente agem sozinhos. É a diversidade microbiana e de espécies da fauna edáfica envolvidas nesse processo que permite decompor estrutural e quimicamente os tecidos complexos de uma planta ou restos de animais (Beare et al.,1992).

A mesofauna do solo compreende os organismos, como ácaros, colêmbolos, alguns grupos de miriápodes, aracnídeos e diversas ordens de insetos, alguns oligoquetos e crustáceos. Esse conjunto de organismos, apesar de extremamente dependentes da umidade do solo, é caracteristicamente terrestre (Swift et al., 1979). As atividades tróficas desses animais incluem tanto o consumo de microrganismos e da microfauna, como a fragmentação de material vegetal em decomposição (Correia \& Andrade, 1999).

A diversidade é um índice composto pelas variáveis: riqueza de espécies (ou grupos de espécies) e eqüitabilidade (ou a uniformidade de repartição dos indivíduos entre os grupos) (Odum, 1993; Begon et al., 1996). O padrão mais marcante é o de poucos grupos com muitos indivíduos e muitos grupos com poucos indivíduos. Entretanto, é importante ressaltar que qualquer medida utilizada fornece uma visão parcial da presença dos organismos edáficos na comunidade (Moço et al., 2005).

Quando se avalia apenas o número de grupos presentes, encontra-se a riqueza deles. Já a uniformidade (e), cuja fórmula é derivada do índice de Shannon (H), é uma medida da eqüidade dos padrões de abundância, ou seja, quando uma comunidade apresenta valores menores, significa que esta é menos uniforme onde a dominância de um ou mais grupos é mais acentuada (Begon et al., 1996). O Índice de Uniformidade de Pielou é um índice de eqüitabilidade em que a uniformidade se refere ao padrão de distribuição dos indivíduos entre as espécies (Moço et al., 2005).

No Brasil, o número de trabalhos sobre a fauna do solo é irrelevante diante da diversidade de ecossistemas do País e do desconhecimento da própria biodiversidade do solo. É possível que muitas espécies sejam extintas antes de serem conhecidas (Merlim, 2005).

Nesse contexto, o presente estudo objetivou avaliar as populações de microrganismos e da mesofauna edáficas, no semi-árido da Paraíba.

\section{MATERIAL E MÉTODOS}

O experimento foi realizado na Reserva Particular do Patrimônio Natural (RPPN), pertencente à Fazenda Tamanduá, localizada no município de Santa Terezinha (PB), situada nas coordenadas geográficas de $7^{\circ} 00$ ' 00 " S e $37^{\circ} 23^{\prime} 00$ ” W, em dois períodos: período 1 , de outubro de 2003 a setembro de 2004 , e período 2, de outubro de 2004 a setembro de 2005 . Na RPPN, foram demarcados transectos, nos quais foram coletadas amostras de solo para avaliação dos microrganismos e da mesofauna edáfica. Segundo a classificação de Köppen, o clima da região se enquadra no tipo Bsh, semi-árido, com médias térmicas anuais superiores a $25^{\circ} \mathrm{C}$ e pluviosidade média anual inferior a $1.000 \mathrm{~mm} \mathrm{ano}^{-1}$, com chuvas irregulares. No município ocorrem associações de Neossolos Litólicos e Luvissolos (Embrapa, 1999). O solo da área experimental apresenta, na profundidade de $0-20 \mathrm{~cm}$, as seguintes características químicas: $\mathrm{pH}$ em água $(1: 2,5)=6,3 ; \mathrm{P}=3,2 \mathrm{mg} \mathrm{dm}-3 \mathrm{~K}^{+}=110,9 \mathrm{mg} \mathrm{dm} \mathrm{dm}^{-3}$; $\mathrm{Na}^{+}=0,05 \mathrm{cmol}_{\mathrm{c}} \mathrm{dm}^{-3} ; \mathrm{Ca}^{2+}=4,28 \mathrm{cmol}_{\mathrm{c}} \mathrm{dm}^{-3} ; \mathrm{Mg}^{2+}$ $=1,78 \mathrm{cmol}_{\mathrm{c}} \mathrm{dm}^{-3} ; \mathrm{H}^{+}+\mathrm{Al}^{3+}=1,71 \mathrm{cmol}_{\mathrm{c}} \mathrm{dm}^{-3} ; \mathrm{e} \mathrm{MO}$ $=12,9 \mathrm{~g} \mathrm{~kg}^{-1}$ (Embrapa, 1997). 
Dados mensais médios de pluviosidade e de temperatura do ar foram obtidos na estação meteorológica, situada na Fazenda Tamanduá. Em todos os pontos de amostragem foi medida a temperatura do solo na superfície e na profundidade de 15,0 cm e determinado o conteúdo de água no solo, de acordo com Tedesco et al. (1995).

\section{Avaliação dos microrganismos do solo}

Para estudo da densidade populacional dos microrganismos no solo, foram coletadas mensalmente, durante o período experimental, três amostras de solo, aleatoriamente, em três transectos, nas profundidades de 0,0-5,0 e 5,0-10,0 cm, utilizandose trado calador. O número de fungos e bactérias foi determinado por meio de unidades formadoras de colônias (UFC), utilizando-se o método de inoculação de suspensões diluídas de solos em meio de cultura BDA (Batata-Dextrose-Ágar), com três repetições por diluição. Das amostras coletadas, retirou-se $1,0 \mathrm{~g}$ de solo e diluiu-se em erlenmeyer, acrescentando-se $10,0 \mathrm{~mL}$ de água destilada, sendo o mesmo procedimento realizado até a diluição $10^{-4}$. Durante a preparação do meio de cultura, colocou-se $1,0 \mathrm{~g}$ de antibiótico, quando destinado à contagem do número de colônias de fungos, para inibir o crescimento de bactérias, e 1,0 g de fungicida do grupo benzimidazol (Benomil), quando destinado à contagem do número de colônias de bactérias, inibindo o crescimento dos fungos, conforme preconizado por Silva (1997).

As placas de Petri com os meios inoculados foram incubadas em temperatura ambiente $\left( \pm 28^{\circ} \mathrm{C}\right)$, com a contagem das colônias dos fungos realizada três dias após a incubação; a contagem das colônias de bactérias foi realizada 10 dias após a incubação, já que estas apresentaram crescimento mais lento. Após incubação, foi obtido, com o auxílio de um contador de colônias, o número de gotas positivas, ou seja, aquelas com crescimento de pelo menos um microrganismo do grupo de interesse.

Para avaliação da população de microrganismos, adotou-se o delineamento em blocos casualizados com três repetições, com os tratamentos em arranjo fatorial $2 \times 12 \times 2$ (profundidade $\times$ meses $\times$ anos). Utilizandose $o$ aplicativo computacional SISVAR (Ferreira, 2000), os dados de colonização de fungos e bactérias foram transformados utilizando $(\log \mathrm{X}+1)$, atendendo, assim, às pressuposições da análise de variância, e as médias, comparadas pelo teste de Tukey $(\alpha=0,05)$.

\section{Avaliação da mesofauna do solo}

Quanto à caracterização da mesofauna do solo, três amostras de solo + serapilheira foram coletadas mensalmente, por transecto, com auxílio de anéis metálicos com 5,2 cm de altura e 4,8 cm de diâmetro. A mesofauna foi extraída pelo método de BerleusseTullgren modificado (Oliveira, 1999), por meio de equipamento adaptado composto de armação de madeira $(143 \times 70 \times 13)$, dividida em dois compartimentos por uma tábua retangular. No compartimento superior havia lâmpadas de $25 \mathrm{~W}$ e, no inferior, uma tábua com furos para colocação dos anéis; abaixo de cada anel havia os funis de polietileno e os frascos de vidro com solução de álcool $80 \%$. As luzes atuaram também como fonte de calor, chegando a atingir $42{ }^{\circ} \mathrm{C}$ na parte superior do anel, fazendo com que os componentes da mesofauna migrassem para baixo até cair nos frascos com solução alcoólica. As amostras foram expostas à luz no extrator por $96 \mathrm{~h}$. Depois de acondicionada, a mesofauna foi identificada com auxílio de uma lente binocular de $40 \mathrm{x}$.

$\mathrm{Na}$ avaliação do comportamento ecológico da mesofauna, mensurou-se o número total de indivíduos (abundância), sendo a riqueza de organismos medida pelos índices de diversidade de Shannon e de eqüitabilidade de Pielou (e). O índice de diversidade de Shannon (H) foi obtido por: $\mathrm{H}=-\sum$ pi log pi, sendo $\mathrm{pi}=\mathrm{ni} / \mathrm{N} ; \mathrm{ni}=$ densidade de cada grupo; $\mathrm{e} \mathrm{N}=\sum$ da densidade de todos os grupos. Este índice assume valores que podem variar de 0 a 5 ; o declínio de seus valores é o resultado de maior dominância de grupos em detrimento de outros (Begon et al., 1996). O Índice de Uniformidade de Pielou (e) é um índice de eqüitabilidade, sendo definido por: $e=\mathrm{H} / \log \mathrm{S}$, em que $\mathrm{H}=$ valor do índice de diversidade de Shannon; e $\mathrm{S}=$ número de grupos funcionais. Na discussão dos dados, utilizou-se o termo "grupo" para identificar os invertebrados de uma mesma ordem.

$\mathrm{O}$ delineamento experimental utilizado foi em blocos casualizados com três repetições, e os tratamentos, em arranjo fatorial $12 \times 2$ (meses $\mathrm{x}$ anos). Por meio da análise de variância, buscou-se a ocorrência significativa sob o aspecto época de coleta, sendo os dados transformados em $\sqrt{x+1}$, atendendo, assim, às pressuposições da análise de variância. As médias para a riqueza de indivíduos da mesofauna foram comparadas pelo teste de Tukey, por meio do qual se obteve a diferença mínima significativa (DMS) a $5 \%$. Na comparação dos grupos de indivíduos coletados na área, utilizaram-se os índices ecológicos Shannon e Pielou.

\section{RESULTADOS E DISCUSSÃO}

Considerando os dois períodos de avaliação quanto à variação mensal na população de fungos e bactérias, representada pela UFC (Unidades Formadoras de Colônias), verificou-se que, no período 1 , houve tendência de superioridade da população de fungos sobre a de bactérias (Figura 1). Isso pode ser atribuído ao tempo de incubação adotado nesse período, no qual a contagem era feita com três dias após a colocação nas placas de Petri - tempo esse considerado insuficiente para o desenvolvimento das UFC de bactérias. Dessa forma, no período 2, aumentou-se o tempo de incubação para 10 dias e verificou-se aumento na população das bactérias. 
Com a redução do conteúdo de água no solo, em maio/2004 (Figura 2), a população fúngica sofreu decréscimos até o mês de junho. As precipitações pluviaias que ocorreram nos meses de junho e julho do período 1 (Figura 2) elevaram o conteúdo de água no solo em torno de $10 \%$, favorecendo o aumento da população de fungos nesses meses, mas com decréscimos nos meses seguintes. Nos meses de janeiro e fevereiro, nos quais se registraram as maiores precipitações pluviaias, os decréscimos foram mais intensos, indicando que a umidade do solo regula as flutuações da população de fungos, onde os extremos limitam 0 desenvolvimento microbiano.

No período 2, observou-se tendência de aumento na população de fungos no mês de novembro, resultado este que surpreendeu, já que as condições eram adversas ao crescimento da microbiota, em virtude da baixa disponibilidade de água no solo $\mathrm{e}$ temperatura do solo acima de $30^{\circ} \mathrm{C}$, além, provavelmente, da reduzida oferta de alimento para esses organismos, em razão do déficit hídrico.

Segundo Cardoso (1992), a adição de resíduos orgânicos favorece o aumento imediato das populações da microbiota e mantém o nível elevado por um período mais ou menos prolongado, até que se esgotem as fontes energéticas. No presente estudo esse comportamento foi confirmado, pois a partir de fevereiro a população voltou a crescer, atingindo um segundo pico em março, mês em que o conteúdo de água no solo era de $16,9 \%$, teor este um pouco mais elevado que o do mês de abril (Figura 1a), período no qual foi registrado maior número de fungos. Subseqüentemente, a população de fungos decresceu de forma mais lenta até o mês de julho, sendo o decréscimo mais acentuado a partir de agosto, quando se registraram baixos conteúdos de água no solo (menos que 1,5\%) e temperaturas elevadas. Variações na população dos microrganismos em decorrência de oscilações no conteúdo de água e na temperatura do solo também foram constatadas por Miranda et al. (1997), ao caracterizarem as populações de fungos, bactérias e actinomicetes em solos com A Chernozêmico na Zona da Mata de Pernambuco, onde observaram que a época úmida favorecia o aumento na população e na diversidade de gêneros fúngicos.

A redução na população de bactérias no período 2 , de dezembro a fevereiro e de maio a julho (Figura 1b),

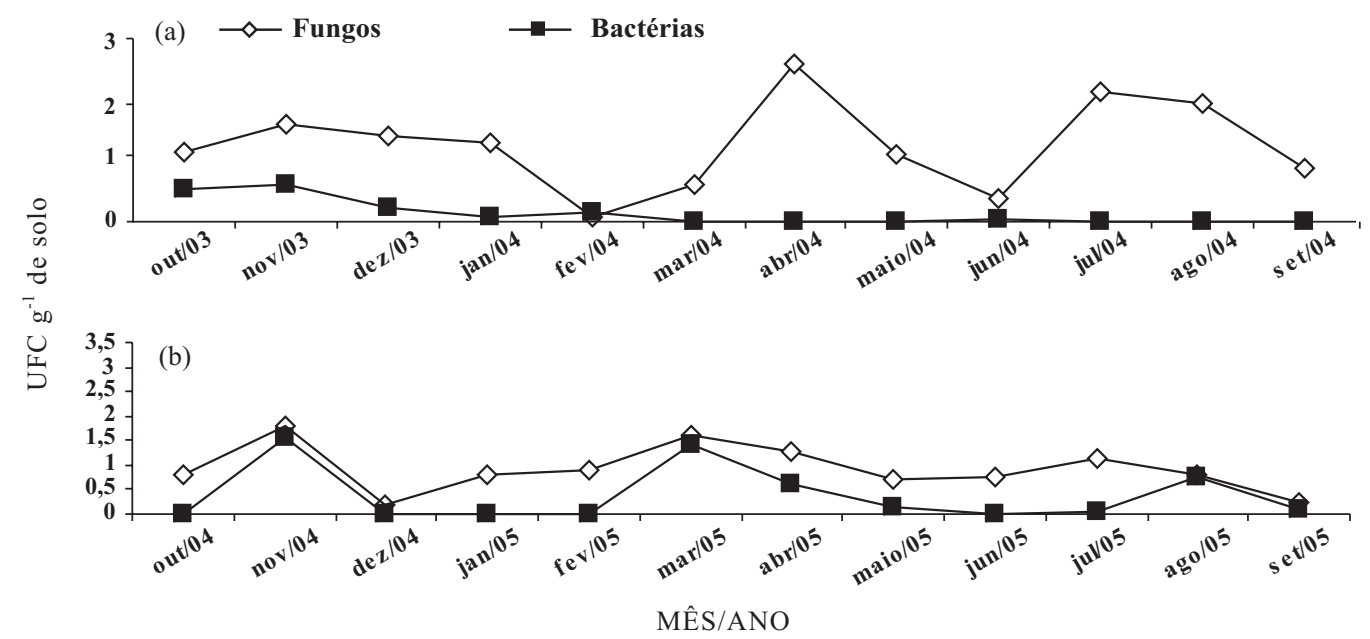

Figura 1. Flutuação da população de fungos e bactérias (UFC) em amostras de solo da área experimental, de outubro de 2003 a setembro de 2004 (a) e de outubro de 2004 a setembro de 2005 (b).

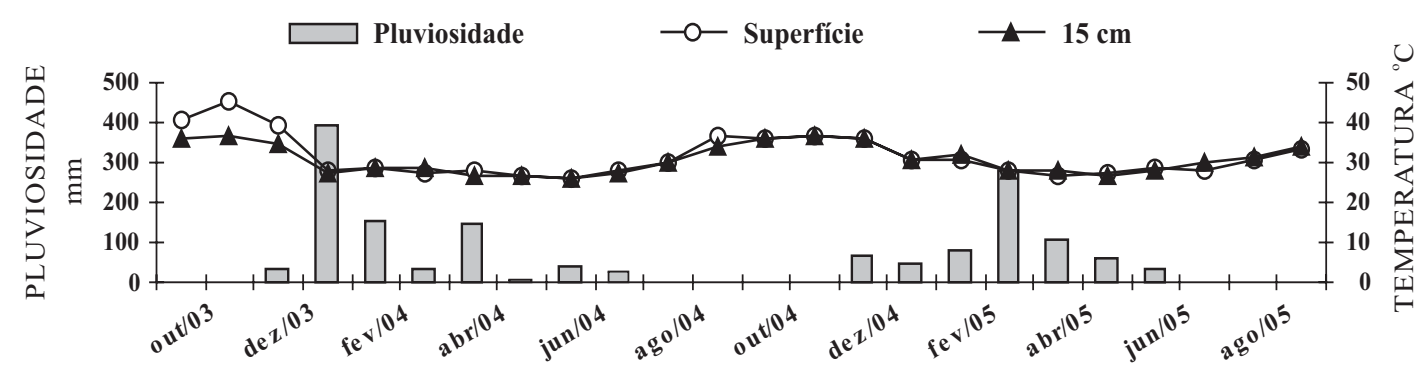

MÊS/ANO

Figura 2. Pluviosidade média e temperaturas do solo na superfície e a $15,0 \mathrm{~cm}$ de profundidade, registradas de outubro/2003 a setembro/2005. 
provavelmente ocorreu devido aos efeitos do estresse hídrico. Por outro lado, o pico no mês de março, que acompanhou o aumento da umidade do solo, pode ter sido favorecido pela maior disponibilidade de resíduos orgânicos decorrente do crescimento do estrato herbáceo na área, aumentando a oferta de nutrientes. De acordo com Miranda et al. (1997), a ocorrência de matéria orgânica e de material mineral pouco alterado nas camadas superficiais favoreceria a maior aeração e disponibilidade de nutrientes, com conseqüente aumento na população de bactérias e fungos. Souto (2002), estudando a população de fungos e bactérias em solo degradado no semi-árido do Estado da Paraíba após a aplicação de diferentes estercos, encontrou maior população de fungos no período de menor índice pluviométrico. Segundo esse autor, o aumento do suprimento hídrico pode ter reduzido ou contribuído para redução no fornecimento de $\mathrm{O}_{2}$, refletindo na população desses organismos, o que justificaria o decréscimo da população de bactérias. Esse comportamento confirma-se no presente estudo. Para Miranda et al. (1997), a umidade é, indiretamente, muito importante, especialmente em solos de textura fina, porque, quanto maior a umidade, menor a disponibilidade de $\mathrm{O}_{2}$ para crescimento microbiano.

De maneira geral, notou-se maior taxa de crescimento de fungos nos períodos mais secos. Isso pode estar relacionado aos valores de $\mathrm{pH}$ do solo, os quais foram ligeiramente ácidos em todos os períodos de amostragem, favorecendo o desenvolvimento dos fungos.

Esses resultados diferem dos encontrados em alguns trabalhos, nos quais, segundo Moreira \& Siqueira (2002), em várias referências é mencionado que fungos são mais adaptados a $\mathrm{pH}$ menores que 5,0 e bactérias, a valores de $\mathrm{pH}$ entre 6 e 8 . De acordo com Brandão (1992), os fungos são encontrados predominantemente em solos ácidos, onde sofrem menor competição; no entanto, esses organismos podem ser encontrados em solos com $\mathrm{pH}$ variando de 3,0 a 9,0 - o valor de pH ótimo é variável com a espécie. Moreira \& Siqueira (2002) salientam a existência de exceções, que devem ser consideradas para evitar generalizações errôneas. Para Calbrix et al. (2005), a heterogeneidade espacial e temporal das comunidades microbianas no solo torna o estudo de biodiversidade microbiana difícil. Na realidade, a relevância de análise de biodiversidade microbiana não só depende das técnicas usadas, mas também da representatividade das amostras.

Quanto à distribuição da população de fungos e bactérias no solo, nas profundidades de $0-5$ e $5-10 \mathrm{~cm}$, não houve diferença estatística entre as duas profundidades testadas, em ambos os períodos (Figura 3a,b).

De todos os micro-habitats do solo, a serapilheira e a rizosfera são os lugares mais ricos em recursos, sendo estes preferidos pelos organismos edáficos para desenvolver seu ciclo de vida. Nessas regiões, os

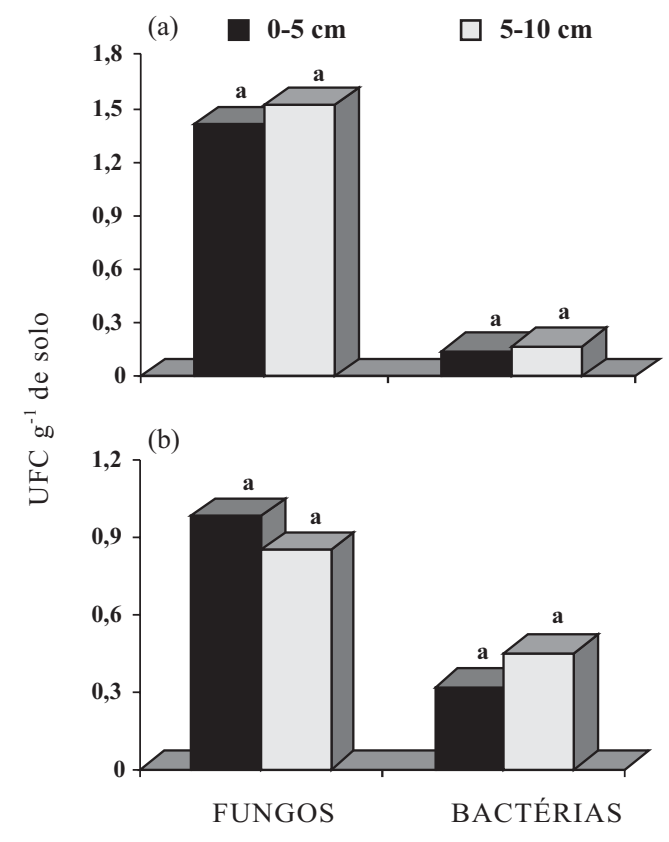

Figura 3. Distribuição da população de fungos e bactérias (UFC), em diferentes profundidades, no período 1 (a): outubro/2003 a setembro/2004 e, no período 2 (b): outubro/2004 a setembro/2005.

microrganismos proliferam usando carboidratos, exsudados, ácidos orgânicos, aminoácidos, enzimas e células liberadas por raízes, folhas e outros materiais vegetais (Brown, 2002). Provavelmente, esse comportamento pode ser reflexo de melhores condições de umidade, aeração, temperatura, $\mathrm{pH}$ e suprimento de nutrientes, que favorecem o desenvolvimento desses organismos. Convém ressaltar que, nas condições de clima e solo onde se desenvolveu o presente estudo, esse foi o comportamento da população de fungos e bactérias, uma vez que cada ambiente apresenta suas características próprias.

\section{Mesofauna do solo}

Durante o período experimental foram coletadas 216 amostras de solo + serapilheira, das quais foram extraídos 699 indivíduos no período 1, distribuídos em 11 grupos, e 989 no período 2 , distribuídos em nove grupos, totalizando 1.688 indivíduos encontrados (Quadro 1).

Observou-se predomínio dos grupos Diptera $(42,5 \%)$, Acarina $(40,3 \%)$ e Collembola $(8,9 \%)$. O grupo Diptera teve representantes em todas as amostragens realizadas, exceto nos meses de outubro e dezembro/2003 e julho/2005. É provável que esses insetos alados sejam agentes importantes na manutenção do equilíbrio ecológico, podendo ser predadores de alguns organismos do solo, como ácaros, colêmbolas, larvas de coleópteros, como também suas larvas podem servir de alimento para os microrganismos (Primavesi, 1999). 
Quadro 1. Número total e freqüência relativa de indivíduos de diferentes grupos de organismos

\begin{tabular}{lrc}
\hline \multicolumn{1}{c}{ Grupos } & $\begin{array}{c}\mathbf{N}^{\mathbf{o}} \text { de individuo } \\
\text { coletado }\end{array}$ & $\begin{array}{c}\text { Freqüência } \\
\text { relativa }\end{array}$ \\
\hline & & $\%$ \\
Collembola & 150 & 8,89 \\
Acarina & 681 & 40,34 \\
Diplopoda & 1 & 0,06 \\
Hymenoptera & 39 & 2,31 \\
Larva de Coleoptera & 11 & 0,65 \\
Diplura & 6 & 0,36 \\
Coleoptera & 63 & 3,73 \\
Araneae & 13 & 0,77 \\
Diptera & 718 & 42,53 \\
Pseudoscorpionida & 3 & 0,18 \\
Protura & 2 & 0,12 \\
Isoptera & 1 & 0,06 \\
Total & 1.688 & 100,00 \\
\hline
\end{tabular}

Outros dois grupos com grande expressividade nas amostragens foram Acarina e Collembola. Segundo Damé et al. (1996), a presença desses indivíduos serve como indicador da condição biológica do solo, dada sua sensibilidade às alterações ambientais. No entanto, a apresentação dos outros grupos não deixa de ser relevante, pois pouco se conhece sobre os organismos que habitam os solos sob a Caatinga e seu papel na ciclagem de nutrientes.

O que também chama a atenção é a alta freqüência relativa de poucos grupos (Diptera, Acarina e Collembola), apresentando os demais um número reduzido de organismos. Para Colinvaux (1986) e Begon et al. (1996), esse comportamento é característico de climas tropicais com estações bem definidas, sendo uma seca e outra úmida. Martins \& Santos (1999) salientam que, em uma comunidade, cada espécie tem abundância diferente, sendo algumas muito abundantes (dominantes) e outras de abundância muito pequena (raras). É provável que os grupos Diptera e Acarina sejam resistentes e perfeitamente adaptados às condições de altas temperaturas e grandes variações no regime hídrico, que ocorreram no presente estudo, sendo considerados, portanto, espécies dominantes. Já o grupo Collembola pode ser considerado intermediário. No entanto, os demais grupos, apesar do número reduzido de indivíduos, são importantes na regulação interna do fluxo de energia desse ecossistema.

Nos três primeiros meses do período 1 , registrouse baixo número de indivíduos da mesofauna (Figura 4), e isso se deveu, provavelmente, aos baixos índices pluviométricos (Figura 2). Com o aumento das chuvas em janeiro e fevereiro, ocorreu aumento no número de indivíduos no mês de fevereiro do período 1, principalmente do grupo Diptera, diferindo estatisticamente dos demais.

Em março, ocorreu decréscimo substancial no número de indivíduos, que se manteve praticamente constante até o final. Já no período 2, verificam-se dois picos em janeiro, mantendo-se constante até fevereiro, e outro pico em abril, com decréscimo pronunciado em junho, mantendo em seguida o mesmo comportamento do período 1.

É provável que esses decréscimos na população da mesofauna nos períodos secos sejam decorrentes da diminuição na oferta de alimento, o que limita a existência de alguns grupos, restando apenas os mais adaptados às condições de escassez hídrica e de alimento, bem como das temperaturas elevadas no solo (Figura 2). Para Primavesi (1999), a densidade de seres vivos no solo é determinada pela quantidade de alimento existente no local.

De modo geral, nos dois anos de estudo, a maior riqueza de indivíduos foi observada no período chuvoso.

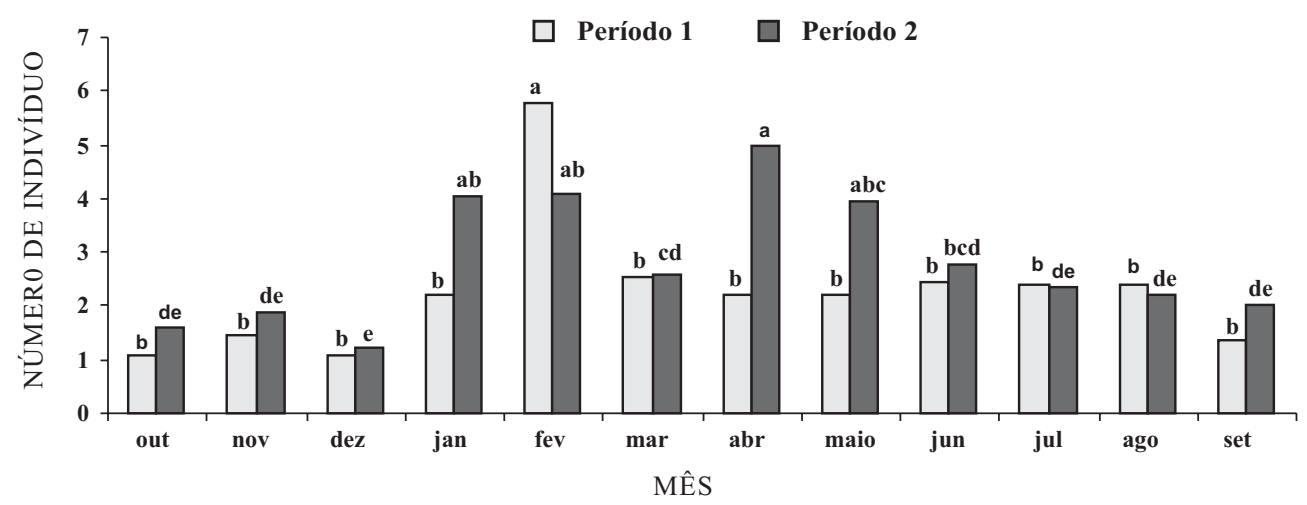

Figura 4. Variação mensal da mesofauna coletada na RPPN da Fazenda Tamanduá no período de outubro de 2003 a setembro de 2004 (período 1) e de outubro de 2004 a setembro de 2005 (período 2). (Valores médios transformados. Letras iguais nas barras de mesma cor não diferem pelo teste de Tukey com p < 0,05). 
Provavelmente, essa riqueza esteja relacionada com o maior conteúdo de matéria orgânica (Poggiani et al., 1996), pois no período chuvoso há maior contribuição do solo rizosférico, pela presença mais efetiva do estrato herbáceo.

Quanto à composição relativa dos grupos taxonômicos, as maiores ocorrências no período de outubro de 2003 a setembro de 2004 foram: Diptera > Acarina $>$ Collembola $>$ Hymenoptera $>$ Coleoptera Os demais indivíduos encontrados não ultrapassaram $1 \%$ do total. Já no período de outubro de 2003 a setembro de 2005, a seqüência dos grupos taxonômicos foi a seguinte: Acarina > Diptera > Collembola > Coleoptera $>$ Hymenoptera $>$ Araneae. Os demais grupos representaram menos que $1 \%$ do total (Figura 5a,b).

A ordem Hymenoptera apresentou mesmo nível de ocorrência nos dois anos de observação. Toledo

(a)

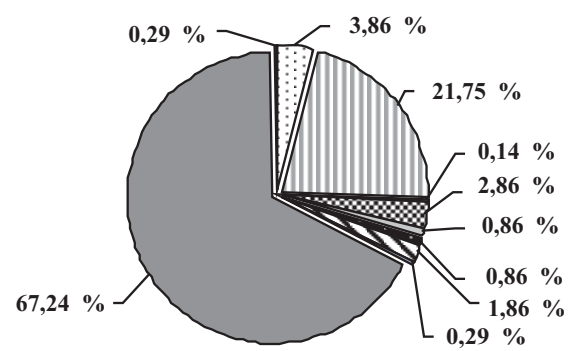

\begin{tabular}{|ll|}
\hline$\square$ Collembola & $\square$ Acarina \\
$\square$ Diplopoda & Ð Hymenoptera \\
$\square$ Larva de Coleoptero & $\square$ Diplura \\
⿴囗十 Coleoptero & $\square$ Araneae \\
$\square$ Diptera & $\square$ Protura \\
\hline
\end{tabular}

(2003) relata que esses insetos são sociais e possuem grande resistência às variações climáticas, o que pode explicar a ocorrência mais constante. Segundo esse autor, os indivíduos pertencentes ao grupo Coleoptera são muito rústicos e resistentes às alterações ambientais e parte deles possui hábito saprófago, atuando na decomposição da serapilheira.

Em relação à diversidade da fauna no período 1 (Quadro 2), verificou-se que ela foi menor no mês de fevereiro, no qual o valor do índice de Shannon registrado foi de 0,38. Essa menor diversidade indica distribuição desuniforme dos indivíduos nesse período, o que é confirmado pelo baixo índice de Pielou encontrado $(0,15)$, sendo 83,5 \% do grupo Diptera e $13,6 \%$ do grupo Acarina, confirmando a reduzida diversidade da fauna nesse período.

De janeiro a abril de 2004, período com maiores índices pluviométricos, foram extraídos 366 indivíduos

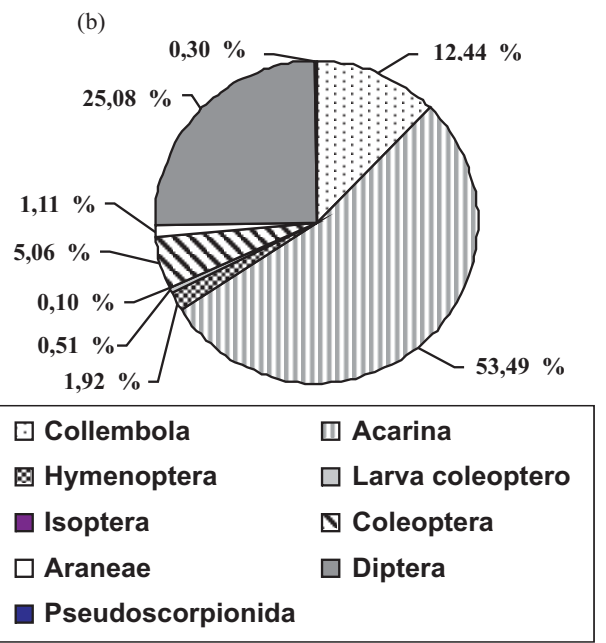

Figura 5. Distribuição dos grupos taxonômicos da mesofauna identificados nas amostras de solo + serapilheira no período 1 (a): outubro/2003 a setembro/2004 e, no período 2 (b): outubro/2004 a setembro/2005.

Quadro 2. Índice de Shannon (H) e índice de Pielou (e) encontrados nos meses de amostragem do período 1 (outubro/2003 a setembro/2004) e do período 2 (outubro/2004 a setembro/2005)

\begin{tabular}{|c|c|c|c|c|c|c|c|c|c|c|c|c|}
\hline \multirow{2}{*}{ Índice } & \multicolumn{12}{|c|}{ Período 1} \\
\hline & Out/03 & Nov & Dez & Jan/04 & Fev & Mar & Abr & Maio & Jun & $\mathbf{J u l}$ & Ago & Set \\
\hline $\mathrm{H}$ & 2,54 & 1,77 & 2,54 & 1,23 & 0,38 & 1,12 & 1,23 & 1,19 & 1,15 & 1,18 & 1,13 & 1,84 \\
\hline \multirow[t]{3}{*}{$\mathrm{e}$} & 8,45 & 1,64 & 8,45 & 0,76 & 0,15 & 0,65 & 0,76 & 0,72 & 0,68 & 0,71 & 0,66 & 1,84 \\
\hline & \multicolumn{12}{|c|}{ Período 2} \\
\hline & Out/04 & Nov & $\operatorname{Dez}$ & Jan/05 & Fev & Mar & Abr & Maio & Jun & $\mathbf{J u l}$ & Ago & Set \\
\hline $\mathrm{H}$ & 1,76 & 1,60 & 2,22 & 0,84 & 0,69 & 1,23 & 0,63 & 0,86 & 1,11 & 1,35 & 1,15 & 1,43 \\
\hline $\mathrm{e}$ & 1,43 & 1,14 & 2,85 & 0,39 & 0,32 & 0,70 & 0,27 & 0,41 & 0,59 & 0,82 & 0,62 & 0,91 \\
\hline
\end{tabular}


do grupo Diptera $(77,9 \%)$ e 87 do grupo Acarina (57\%). É provável que as condições favoráveis no microclima do solo na estação úmida, associadas à presença mais efetiva dos estratos herbáceo e arbustivo, tenham aumentado a oferta de alimento para esses organismos - daí o aumento observado. Esses resultados corroboram os encontrados por Ducatti (2002), que verificou maior quantidade de ácaros nas amostras coletadas no período quente e úmido, condição satisfatória para a presença dos ácaros na camada superficial do solo.

O maior valor do índice de Shannon no período 1 foi encontrado nos meses de outubro e dezembro de 2003, provavelmente em razão do menor número de organismos encontrados e da pequena variação da riqueza de grupos funcionais da fauna (apenas dois grupos em cada um desses meses), elevando a eqüitabilidade, a qual é explicada pelo maior valor no índice de Pielou, que foi de 8,45, em ambos os meses. Para Walker (1989), a diversidade de espécies está associada a uma relação entre o número de espécies (riquezas de espécies) e a distribuição do número de indivíduos entre as espécies (eqüitabilidade).

O menor valor do índice de Shannon no período 2 foi registrado no mês de abril, sendo confirmado no índice de Pielou, que também registrou os valores mais baixos (Quadro 2). Isso indica maior densidade de indivíduos de determinado grupo e menor uniformidade quanto às espécies. Os resultados obtidos no mês de abril de 2005 foram semelhantes aos obtidos em fevereiro de 2004, com predomínio do grupo Díptera, com $132(57,4 \%)$ indivíduos capturados, e do grupo
Acarina, com 76 (33,0 \%) indivíduos. Confirma-se, também, o acréscimo da população de ácaros no período mais úmido, como foi verificado no período 1 . A população desses organismos nos meses de maior oferta hídrica, de janeiro a abril de 2005, foi de 291 indivíduos, com redução para 231 nos meses subseqüentes.

Ao avaliar a distribuição de cada grupo quanto à abundância e uniformidade (Quadro 3), verifica-se, no período 1 , que entre os indivíduos capturados o número de indivíduos do grupo Diptera foi o maior: 470. Os baixos valores obtidos nos índices testados $(\mathrm{H}=0,17$; $e=0,06)$ evidenciam que a alta densidade de indivíduos do grupo Diptera pode ter reduzido a diversidade no ecossistema.

No período 2, o grupo Acarina apresentou o menor índice de Shannon, seguido pelos grupos Diptera, Collembola e Coleoptera, sendo, portanto, esses grupos os de maior freqüência. Foi verificada, então, diferença entre a ordem de abundância de cada grupo de um ano para o outro, quando o número de indivíduos de alguns grupos taxonômicos sofreu decréscimo, como foi o caso do grupo Diptera; já outros aumentaram, como os grupos Acarina e Coleoptera. Essas mudanças na estrutura da comunidade de um ano para o outro podem decorrer da maior ou menor oferta de alimento disponível via serapilheira, que nesse período foi de $1.947 \mathrm{~kg} \mathrm{ha}^{-1}$, tendo sido superior ao depositado no período 1 , com $1.291 \mathrm{~kg} \mathrm{ha}^{-1}$. Portanto, essas substituições de espécies e rearranjos na abundância fazem parte do desenvolvimento do ecossistema em busca do equilíbrio.

Quadro 3. Número de indivíduos e valores obtidos pelos índices de Shannon (H) e de Pielou (e) para os grupos da mesofauna coletados no período 1 (outubro/2003 a setembro/2004) e do período 2 (outubro/ 2004 a setembro/2005)

\begin{tabular}{|c|c|c|c|c|c|c|}
\hline \multirow{3}{*}{ Grupo } & \multirow{2}{*}{\multicolumn{2}{|c|}{$\begin{array}{c}\text { Número de } \\
\text { indivíduo coletado }\end{array}$}} & \multicolumn{4}{|c|}{ Índice } \\
\hline & & & \multicolumn{2}{|c|}{ Período 1} & \multicolumn{2}{|c|}{ Período 2} \\
\hline & Período 1 & Período 2 & Shannon & Pielou & Shannon & Pielou \\
\hline Collembola & 27 & 123 & 1,41 & 0,50 & 0,91 & 0,30 \\
\hline Acarine & 152 & 529 & 0,66 & 0,23 & 0,27 & 0,09 \\
\hline Diplopoda & 1 & 0 & 2,84 & 1,00 & 0 & 0 \\
\hline Hymenoptera & 20 & 19 & 1,54 & 0,54 & 0,58 & 0,19 \\
\hline Larva de Coleóptero & 6 & 5 & 2,07 & 0,73 & 0,44 & 0,15 \\
\hline Diplura & 6 & 0 & 2,07 & 0,73 & 0 & 0 \\
\hline Coleoptera & 13 & 50 & 1,73 & 0,61 & 1,30 & 0,43 \\
\hline Araneae & 2 & 11 & 2,54 & 0,89 & 1,95 & 0,65 \\
\hline Diptera & 470 & 248 & 0,17 & 0,06 & 0,60 & 0,20 \\
\hline Protura & 2 & 0 & 2,54 & 0,89 & 0 & 0 \\
\hline Isoptera & $0^{(1)}$ & 1 & 0 & 0 & 3,00 & 1,0 \\
\hline Pseudoscorpionida & 0 & 3 & 0 & 0 & 2,52 & 0,84 \\
\hline
\end{tabular}

(1) Nenhum organismo extraído. 
Salienta-se que os valores de diversidade utilizados são apenas estimativas da população desses organismos, os quais, segundo Fabricante et al. (2006), sofrem interferência direta do uso de metodologias diferenciadas, tamanho amostral e outras variáveis.

Entretanto, estudos mais específicos sobre o comportamento dos organismos edáficos em área de Caatinga devem ser conduzidos para consolidar o conhecimento necessário quanto à sustentabilidade desse ecossistema, de modo a definir estratégias de conservação e manejo.

\section{CONCLUSÕES}

1. A população de fungos foi superior à de bactérias em todos os períodos estudados.

2. Os grupos predominantes da mesofauna foram Diptera, Acarina e Collembola.

3. A composição relativa dos grupos taxonômicos variou de um ano para outro. Em 2003, foi: Diptera > Acarine $>$ Collembola $>$ Hymenoptera $>$ Coleoptera; $\mathrm{e}$ em 2004: Acarina > Diptera > Collembola > Coleoptera $>$ Hymenoptera > Aranea.

4. Os grupos que apresentaram menores índices de Shannon e de Pielou, indicando maior densidade de indivíduos, foram: Diptera, Acarina, Collembola e Hymenoptera.

\section{AGRADECIMENTOS}

Os autores agradecem à CAPES e ao proprietário da Fazenda Tamanduá, Sr. Pierre Landolt, o apoio financeiro e institucional para realização deste trabalho.

\section{LITERATURA CITADA}

BEARE, M.H.; PARMELEE, R.W.; HENDRIX, P.F. \& CHENG, W. Microbial and faunal interactions and effects on litter nitrogen and decomposition in agroecosystems. Ecol. Monogr., 62: 569-591, 1992.

BEGON, M.; HARPER, J.L. \& TOWNSEND, C.R. Ecology: Individuals, populations and communities. 3.ed. Oxford, Blackwell Science, 1996. 1068p.

BRANDÃO, E.M. Os componentes da comunidade microbiana do solo. In: CARDOSO, E.J.B.N.; TSAI, S.M. \& NEVES, M.C.P., coords. Microbiologia do solo. Campinas, Sociedade Brasileira de Ciência do Solo, 1992. p.1-15.

BROWN, G.G. Papel das interações biológicas no funcionamento edáfico: Interações entre a fauna e os microrganismos do solo. In: FERTIBIO, Rio de Janeiro, 2002. Anais. Rio de Janeiro, Sociedade Brasileira de Ciência do Solo, 2002. p.1-4.
CALBRIX, R.; LAVAL, K. \& BARRAY, S. Analysis of the potential functional diversity of the bacterial community in soil: A reproducible procedure using solecarbon-source utilization profiles. Eur. J. Soil Biol., 41:11$20,2005$.

CARDOSO, E.J.B.N. Ecologia microbiana do solo. In: CARDOSO, E.J.B.N.; TSAI, S.M. \& NEVES, M.C.P., cords. Microbiologia do solo. Campinas, Sociedade Brasileira de Ciência do Solo, 1992. p.33-39.

COLINVAUX, P. Ecology. New York, John Wiley \& Sons, 1996. 725p.

CORREIA, M.E.F. \& ANDRADE, A.G. Formação da serapilheira e ciclagem de nutrientes. In: SANTOS, G.A. \& CAMARGO, F.A.O., eds. Fundamentos da matéria orgânica do solo: Ecossistemas tropicais e subtropicais. Porto Alegre, Gênesis, 1999. p.197-225.

DAMÉ, P.R.V.; QUADROS, F.L.F.; KERSTING, C.E.B. \& TRINDADE, J.P.P. Efeitos da queima seguida de pastejo ou diferimento sobre o resíduo, temperatura do solo e mesofauna de uma pastagem natural. R. Ci. Rural, 26:391396, 1996.

DUCATTI, F. Fauna edáfica em fragmentos florestais e em áreas reflorestadas com espécies da Mata Atlântica. Piracicaba, Escola Superior de Agricultura "Luiz de Queiroz", 2002. 70p. (Tese de Mestrado)

EMPRESA BRASILEIRA DE PESQUISA AGROPECUÁRIA EMBRAPA. Centro Nacional de Pesquisas de Solos. Sistema brasileiro de classificação de solos. Brasília, Embrapa Produção de Informação, 1999. 412p.

EMPRESA BRASILEIRA DE PESQUISA AGROPECUÁRIA EMBRAPA. Centro Nacional de Pesquisas de Solos. Manual de métodos de análise de solo. 2.ed. Rio de Janeiro, 1997. 212p.

FABRICANTE, J.R.; ANDRADE, L.A. \& MARQUES, F.J. Componente epifítico vascular ocorrente em árvores urbanas. Cerne, 12:399-405, 2006.

FERREIRA, D.F. Análises estatísticas por meio do SISVAR para Windows 4.0. In: REUNIÃO ANUAL DA REGIÃO BRASILEIRA DA SOCIEDADE INTERNACIONAL DE BIOMETRIA, 45., São Carlos, 2000. Anais. São Carlos, Universidade Federal de São Carlos, 2000. p.255-258.

LEJON, D.P.H.; CHAUSSOD, R.; RANGER, J. \& RANJARD, L. Microbial community structure and density under different tree species in an acid forest (Morvan, France). Microbiol. Ecol., 50:614-625, 2005.

MARTINS, F.R. \& SANTOS, F.A.M. Técnicas usuais de estimativa da biodiversidade. R. Holos, 1:236-267, 1999.

MERLIM, A.O. Macrofauna edáfica em ecossistemas preservados e degradados de araucária no Parque Estadual de Campos do Jordão, SP. Piracicaba, Escola Superior de Agricultura "Luiz de Queiroz", 2005. 89p. (Tese de Mestrado) 
MIRANDA, C.S.S.; FERREIRA, M.G.V.X. \& MENEZES, M. Atividade biológica de solos com A Chernozêmico na Zona da Mata Norte de Pernambuco. In: CONGRESSO BRASILEIRO DE CIÊNCIAS DO SOLO, 26., Rio de Janeiro, 1997. Anais. Rio de Janeiro, Sociedade Brasileira de Ciência do Solo, 1997. p.1-4.

MOÇO, M.K.S.; GAMA-RODRIGUES, E.F.; GAMARODRIGUES, A.C. \& CORREIA, M.E.F. Caracterização da fauna edáfica em diferentes coberturas vegetais na região norte fluminense. R. Bras. Ci. Solo, 29:565-571, 2005.

MOREIRA, F.M.S. \& SIQUEIRA, J.O. Microbiologia e bioquímica do solo. Lavras, Universidade Federal de Lavras, 2002. 625p.

ODUM, E.P. Ecologia. Rio de Janeiro, Guanabara, 1993. 434p.

OLIVEIRA, A.R. Efeito do Baculovirus anticarsia sobre Oribatida edáficos (Arachinida: Acari) na cultura de soja. São Paulo, Universidade de São Paulo, 1999. 69p. (Tese de Mestrado)

POGGIANI, F.; OLIVEIRA, R.E. \& CUNHA, G.C. Práticas de ecologia florestal. Piracicaba, 1996. p.1-44. (Documentos Florestais, 16)

PRIMAVESI, A. Manejo ecológico do solo. São Paulo, Nobel, 1999. $549 \mathrm{p}$
SILVA, A.P. Atributos pedoecológicos e censitários relativos à desertificação: Município de Soledade, Paraíba. Areia, Universidade Federal da Paraíba, 1997. 56p. (Trabalho Monográfico)

SOUTO, P.C. Estudo da dinâmica de decomposição de estercos na recuperação de solos degradados no semi-árido paraibano. Areia, Universidade Federal da Paraíba, 2002. 110p. (Tese de Mestrado)

SWIFT, M.J.; HEAL, O.W. \& ANDERSON, J.M. Decomposition in terrestrial ecosystems. Berkeley, University of California Press, 1979. p.66-117.

TEDESCO, J.M.; VOLKWEISS, S.J. \& BOHNEN, H. Análises de solo, plantas e outros materiais. Porto Alegre, Universidade Federal do Rio Grande do Sul, 1995. 188p. (Boletim Técnico, 5)

TOLEDO, L.O. Aporte de serrapilheira, fauna edáfica e taxa de decomposição em áreas de floresta secundária no Município de Pinheiral, RJ. Seropédica, Universidade Federal Rural do Rio de Janeiro, 2003. 80p. (Tese de Mestrado)

WALKER, D. Diversity and stability. In: EDWARDS, C.A., ed. Ecological concepts. Oxford, Blackwell Scientific Public, 1989. p.115-146. 